\title{
CALIBRATION OF THERMOLUMINESCENT DETECTORS IN HP(0.07) UNITS BY USING AN X-RAY TUBE AND A ${ }^{137}$ CS SOURCE
}

\author{
Małgorzata Wrzesień \\ University of Lodz, Łódź, Poland \\ Faculty of Physics and Applied Informatics, Department of Nuclear Physics and Radiation Safety
}

\begin{abstract}
Background: The method of measuring doses based on the thermoluminescence phenomenon is not an absolute method. For this reason, to obtain correct results, it is necessary to calibrate detectors in the known radiation field. This paper presents a method for calibrating thermoluminescent detectors used in the measurement of personal dose equivalents $(\mathrm{H} p(0.07))$ obtained by nuclear medicine facility personnel when handling the ${ }^{99 \mathrm{~m}} \mathrm{Tc}$ radionuclide. Material and Methods: The authors used self-developed high-sensitivity thermoluminescent detectors and a HF320C X-ray unit, as well as a rod phantom. Dosimeters were calibrated in accordance with the ISO 4037-3 standard. During the measurements a vial containing a ${ }^{99 \mathrm{~m}} \mathrm{Tc}$ radionuclide with well-known activity was also used. The energy characteristics were supplemented by using a ${ }^{137} \mathrm{Cs}$ source (irradiator ${ }^{60} \mathrm{Co} /{ }^{137} \mathrm{Cs}$ ). Results: The value of the calibration coefficient for $118 \mathrm{keV}$ energy energy was $(1.90 \pm 0.02) \times 10^{-5} \mathrm{mSv} / \mathrm{imp}$. Taking into account the correction factor specified for of $140 \mathrm{keV}$ energy at 0.962 , the value of the calibration coefficient for $140 \mathrm{keV}$ energy was determined as $(1.83 \pm 0.02) \times 10^{-5} \mathrm{mSv} / \mathrm{imp}$. Conclusions: Verification of the calibration coefficient determined for $140 \mathrm{keV}$ energy carried out with a vial containing a ${ }^{99 \mathrm{~m}} \mathrm{Tc}$ radionuclide confirmed the correctness of the procedure. Med Pr. 2019;70(6):669-73
\end{abstract}

Key words: thermoluminescence, $\mathrm{H} p(0.07)$, calibration, $\mathrm{X}$-ray, dosimetry, nuclear medicine

Corresponding author: Małgorzata Wrzesień, University of Lodz, Faculty of Physics and Applied Informatics, Department of Nuclear Physics and Radiation Safety, Pomorska 149/153, 90-236 Łódź, Poland, e-mail: mwrzesien@uni.lodz.pl Received: May 7, 2019, accepted: June 7, 2019

\section{INTRODUCTION}

Thermoluminescent detectors (TLDs) belong to the group of relative detectors, which means that they need to be calibrated before dosimetry measurements are started. Often, this procedure requires the use of appropriate phantoms, such as, e.g., the assessment of the personal dose equivalent $\mathrm{H} p(0.07)$ or $\mathrm{H} p(10)$. In addition, TLDs are characterized by the fact that their response to the absorbed dose depends on the radiation energy to which the detectors have been exposed. This, in turn, means that energy and the type of radiation in the calibration process need to be taken into consideration. Known and used reference sources of gamma radiation include ${ }^{60} \mathrm{Co}$ (energy of gamma radiation $-1250 \mathrm{keV}$ ), ${ }^{137} \mathrm{Cs}(662 \mathrm{keV})$ and ${ }^{241} \mathrm{Am}(59.5 \mathrm{keV})$. However, the energy of gamma radiation emitted by the ${ }^{99 \mathrm{~m} T c}$ radionuclide is $140 \mathrm{keV}$. X-ray remains a viable option. The use of $\mathrm{X}$-rays brings the unquestionable advantage of using a source that emits radiation with the energy closest to $140 \mathrm{keV}$. However, the radiation spectrum in this case is regrettably not monoenergetic.
The proposed work presents a description of the procedure for calibrating thermoluminescent detectors in $\mathrm{H} p(0.07)$ units using an $\mathrm{X}$-ray tube and a ${ }^{137} \mathrm{Cs}$ source. The calibration factor obtained in this procedure was used to assess the hand exposure of nuclear medicine department workers when handling the ${ }^{99 \mathrm{~m}} \mathrm{Tc}$ radionuclide [1-7].

\section{MATERIAL AND METHODS}

The measurements were performed at the Secondary Standard Laboratory of the Nofer Institute of Occupational Medicine in Łódź. The authors used self-developed high-sensitivity thermoluminescent detectors MCP-N - LiF:Mg,Cu,P. The detectors were calibrated using the narrow spectrum obtained with a $30-300 \mathrm{kV}$ HF320C X-Ray unit (tube potential $150 \mathrm{kV}$, additional filtration $2.5 \mathrm{~mm}$ of tin). The dose rate value was measured by the ionization chamber of the UNIDOS. Dosimeters were calibrated in accordance with the ISO 4037-3 [8] standard in the range 0.05-30 mGy as the air kerma. The $\mathrm{H} p(0.07)$ for fingers was calculated taking 
into account the conversion coefficient $\mathrm{h}_{p \mathrm{~K}}(0.07)$ given in the ISO International Standard. A rod phantom was used during the measurements. Figure 1 presents the location of TLDs on the rod phantom.

Correction was introduced on the difference between the energies of X-ray quantum and ${ }^{99 \mathrm{~m}} \mathrm{Tc}$ gamma photons. This was accomplished by testing the calibration curve within the 100-250 keV photon energy range. The energy characteristic was supplemented by using a ${ }^{137} \mathrm{Cs}$ source. The results were compared to TLD calibration with a ${ }^{99 \mathrm{~m}} \mathrm{Tc}$ source. The activity of the radionuclide ${ }^{99 \mathrm{~m}} \mathrm{Tc}$ was measured using PTW Curiementor 2 (with an ionization chamber placed in a lead shield). During the calibration coefficient verification procedure the value of doses was changed by increasing the exposure time.

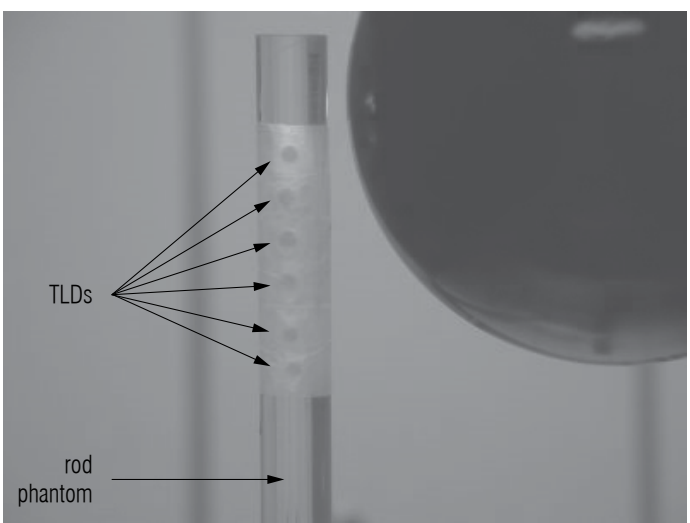

Figure 1. Location of thermoluminescent detectors (TLDs) on the rod phantom (a visible fragment of the ionization chamber in the background)
The gamma radiation dose rate was calculated taking into account the activity of the ${ }^{99 \mathrm{~m}} \mathrm{Tc}$ radionuclide and the radiation source distance from the detectors. Figure 2 presents the idea of calibration coefficient verification by using TLDs and a vial containing a ${ }^{99 \mathrm{~m} T c}$ radionuclide with well-known activity.

The detectors were read out using an RA' 94 reader, produced by Mikrolab Co. The TLDs used were subjected to a typical process of annealing in a TLD oven produced by PTW.

\section{RESULTS}

The different reactions of detectors to a dose when changing the radiation energy mean that an individual calibration coefficient needs to be determined for each

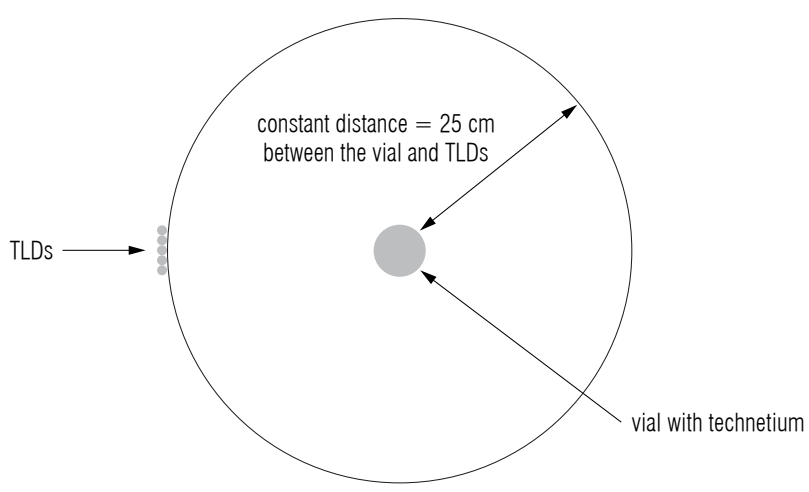

Figure 2. Verification procedure of the calibration coefficient with thermoluminescent detectors (TLDs) and a vial with the ${ }^{99 \mathrm{~m}} \mathrm{Tc}$ radionuclide

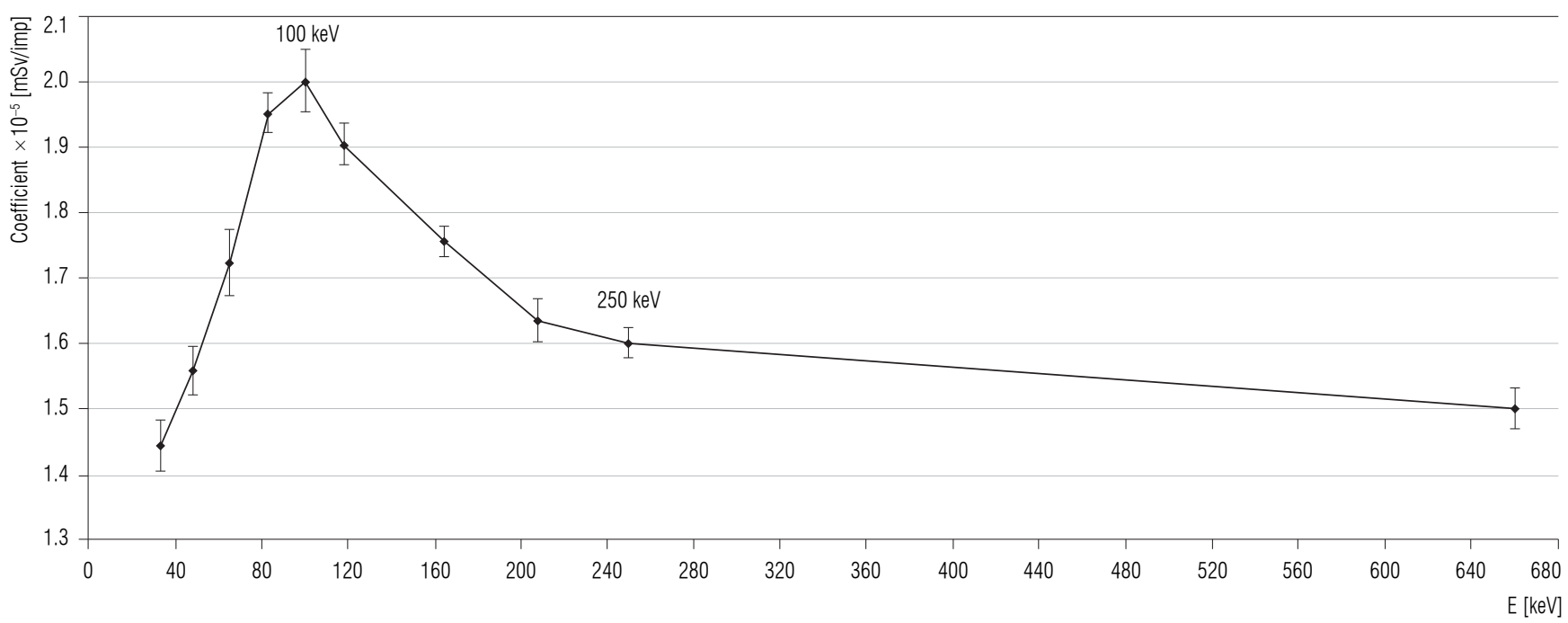

Figure 3. Change in the calibration coefficient depending on the radiation energy (E) 


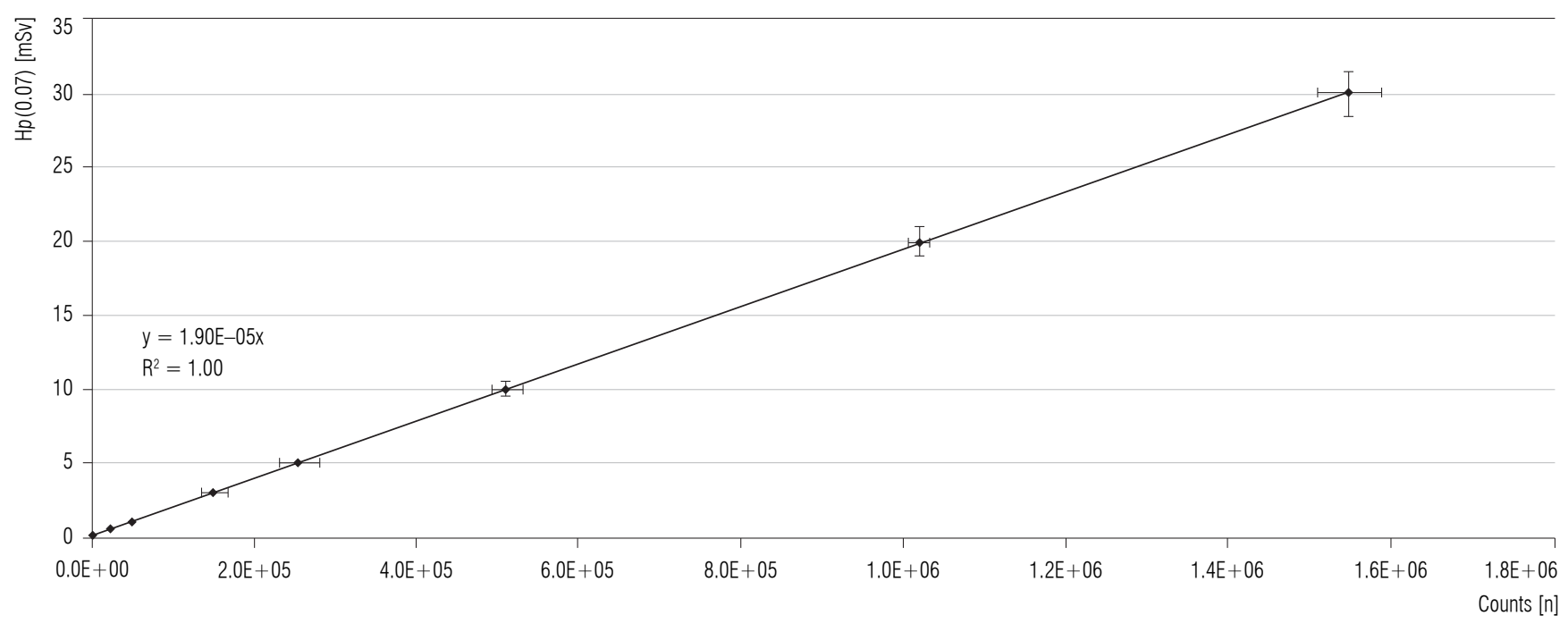

The detectors placed on the rod phantom were exposed to X-rays with $118 \mathrm{keV}$ energy.

Figure 4. Calibration curve

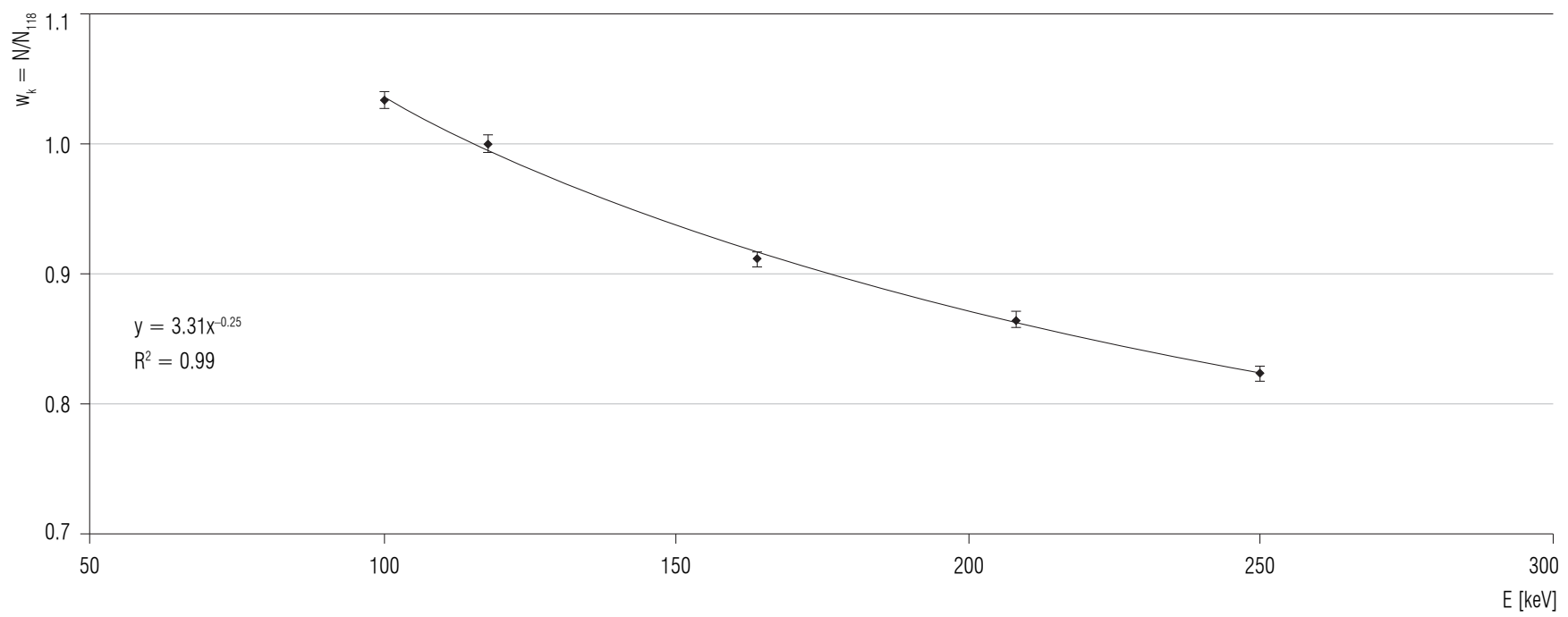

Figure 5. Correction coefficient values $\left(\mathrm{w}_{\mathrm{k}}\right)$ depending on the radiation energy (E)

energy level (33-660 keV). Figure 3 shows the change curve of the calibration coefficient depending on the radiation energy.

The calibration curve for the energy of radiation equal to $118 \mathrm{keV}$ is presented in Figure 4.

The calibration factor for $118 \mathrm{keV}$ energy was $(1.90 \pm$ $0.02) \times 10^{-5} \mathrm{mSv} / \mathrm{imp}$.

\section{DISCUSSION}

As can be seen in Figure 3, the change of the coefficient in the energy range $100-250 \mathrm{keV}$ is $20 \%$. Therefore, it was necessary to calculate the correction factor, $\mathrm{w}_{\mathrm{k}}=\mathrm{N} /$ $\mathrm{N}_{118}$, depending on the energy the detectors were exposed to. The coefficient was referred to the average number of counts obtained for $118 \mathrm{keV}$ energy. The dependence of the correction coefficient on energy in the energy range $100-250 \mathrm{keV}$, together with the function describing these changes, was determined. It was presented in Figure 5.

The correction coefficient for $140 \mathrm{keV}$ energy, i.e., the energy of gamma radiation emitted by technetium was determined as 0.962 .

Taking into account the correction factor value (0.962) for $140 \mathrm{keV}$ energy, the authors determined 


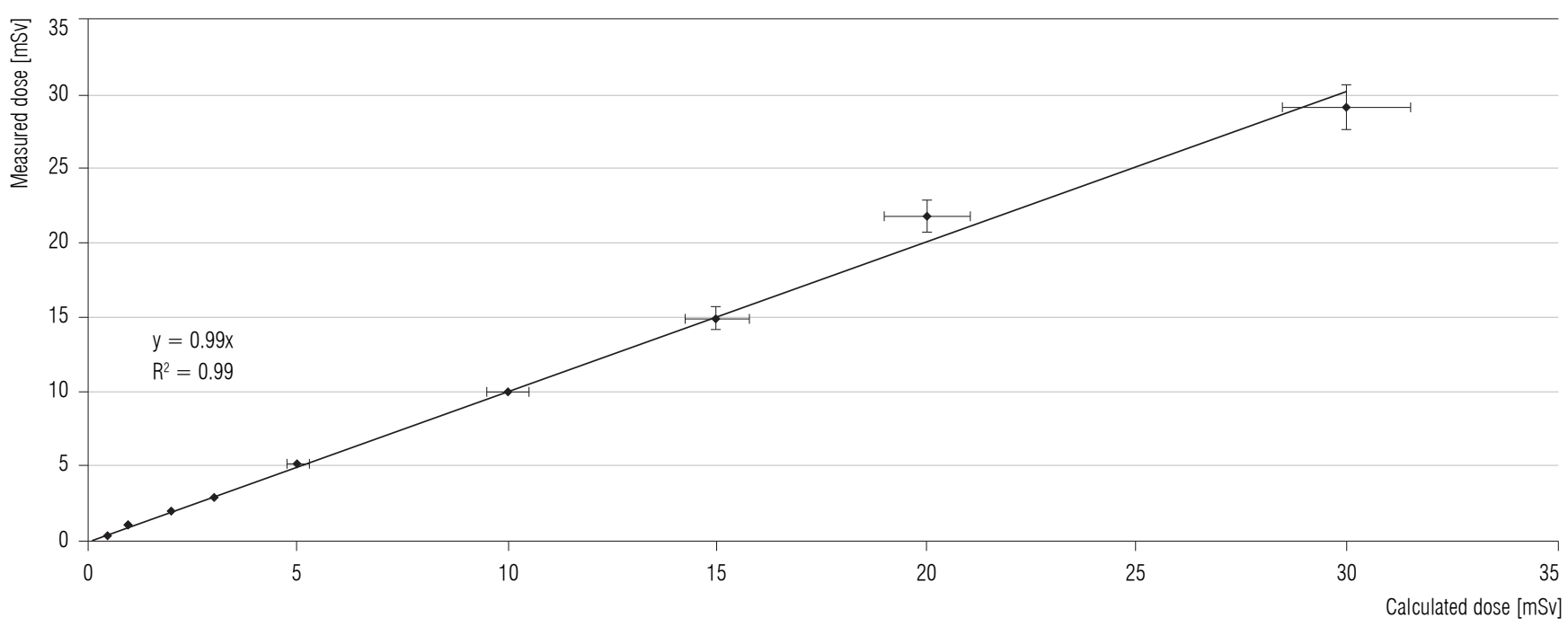

Figure 6. Relationship between the dose measured with a thermoluminescent detector and the theoretically calculated dose

the value of the calibration coefficient for the energy of gamma radiation emitted by the ${ }^{99 \mathrm{~m}} \mathrm{Tc}$ radionuclide. The value of the calibration coefficient was $(1.83 \pm 0.02) \times$ $10^{-5} \mathrm{mSv} / \mathrm{imp}$.

The calibration coefficient determined as described above was subjected to the verification procedure.

The verification of the calibration coefficient consisted in comparing the dose measured by using the TLDs (taking into account the value of the calibration coefficient) with the "theoretical" dose that the detectors should register. The "theoretical" dose takes into account the value of the dose rate of gamma radiation emitted by the ${ }^{99 \mathrm{~m}} \mathrm{Tc}$ radionuclide at the point where the TLD is located, as well as the exposure time.

Figure 6 shows the relationship between the measured dose and the calculated theoretical dose [9].

The resultant correlation between those two types of calibration was linear and orthogonal.

\section{CONCLUSIONS}

The presented results confirm the correctness of the implementation of the thermoluminescence detector calibration in units of $\mathrm{H} p(0.07)$. During this procedure the $\mathrm{X}$-ray tube, a ${ }^{137} \mathrm{Cs}$ source and the ${ }^{99 \mathrm{~m}} \mathrm{Tc}$ radionuclide were used. The verification of the calibration coefficient proved the correct calculation of this coefficient value.

\section{REFERENCES}

1. Wrzesień M, Olszewski J, Jankowski J. The influence of procedures performed with radiopharmaceutics on equivalent dose to the hands of the staff. In: Second European IRPA Congress on Radiation Protection. Radiation protection: From Knowledge to Action. Proceedings of full papers [CDROM]; 2006 May 15-19; Paris, France. Paris: International radiation Protection Association; 2006. p. 6.

2. Wrzesień M, Olszewski J, Jankowski J. Hand exposure to ionising radiation of nuclear medicine workers. Radiat Prot Dosimetry. 2008;130:325-30, https://doi.org/10.1093/rpd/ ncn057.

3. Wrzesień M, Napolska K. Investigation of radiation protection of medical staff performing medical diagnostic examinations by using PET/CT technique. J Radiol Prot. 2015; 35:197-207, https://doi.org/10.1088/0952-4746/35/1/197.

4. Wrzesień M, Napolska K, Olszewski J. Exposure of personnel and public due to using 153Sm-labelled EDTMPQUADRAMETTM in nuclear medicine procedures. Radiat Prot Dosimetry. 2016;168:396-400, https://doi.org/10.1093/ $\mathrm{rpd} / \mathrm{ncv} 353$.

5. Wrzesień M, Albiniak Ł. Hand exposure of workers in 18F-FDG production centre. J Radiol Prot. 2016;36:N67-76, https://doi.org/10.1088/0952-4746/36/4/N67.

6. Wrzesien M. [Simplicity or complexity of the radiopharmaceutical production process in the light of optimization of radiation protection of staff $-99 \mathrm{mTc}$ versus $18 \mathrm{~F}]$. Med Pr. 2018;69:317-27, https://doi.org/10.13075/mp.5893.00687. Polish.

7. Wrzesien M. The effect of work system on the hand exposure of workers in 18F-FDG production centres. Australas Phys Eng Sci Med. 2018;41:541-8, https://doi.org/10.1007/ s13246-018-0644-9.

8. ISO-4037-3. X and gamma reference radiation for calibrating dosemeters and doserate meters and determining their 
response as a function of photon energy: Part 3. Calibration of area and personal dosemeters and the measurement of their response as a function of energy and angle of incidence. Geneva: International Organization for Standardization; 1999.
9. Gostkowska B. Wielkości, jednostki i obliczenia stosowane w ochronie radiologicznej. Warszawa: Centralne Laboratorium Ochrony Radiologicznej; 2011.

This work is available in Open Access model and licensed under a Creative Commons Attribution-NonCommercial 3.0 Poland License - http://creativecommons.org/licenses/by-nc/3.0/pl/deed.en. 